\title{
THREE-DIMENSIONAL ANALYSIS OF SOIL-PILE-STRUCTURE INTERACTION PROBLEM ON HIGH RISE BUILDING ON IMPROVED SOFT SOIL
}

\author{
Thanapon Tipsunavee ${ }^{1}$ and Goran Arangjelovski ${ }^{2}$ \\ ${ }^{1,2}$ King Mongkut's University of Technology Thonburi, Bangkok, Thailand \\ *Corresponding Author, Received: 11 Nov. 2021, Revised: 01 Dec. 2021, Accepted: 18 Dec. 2021
}

\begin{abstract}
This study presents the numerical simulation of flexible wall barrel soil-pile-structure interaction analysis. Soil-Structure Interaction (SSI) is usually assumed beneficial during an earthquake. However, SSI can also increase permanent deformation and decrease the stiffness of the pile foundation system which affects seismic response and displacement in the overall structure, especially high-rise buildings. Non-linear 3D FEM models with a gap/slap mechanism have been developed in ABAQUS to simulate the effect of soil-pile-structure interaction (SPSI). The objectives of this research are to study the effect of SPSI on soil response, kinematic properties of the superstructure, and the modeling of SPSI problem with the superstructure, and to increase horizontal stiffness of foundation system by using the cement-mixing method. The analyses in this study include superstructure analysis with fix-based, SPSI, and SPSI with cement-mixing. The constitutive models in this study are Mohr-Coulomb for soil material and Linear-elastic for the upper structure. The calibration of the flexible wall barrel modeling technique was successfully calibrated with a shaking table reference case with some variation of the results. It is observed that SPSI provides flexibility and damping to the superstructure. The gap/slap mechanism is clearly observed on the contact surfaces between soil and superstructure at a shallow level. Cement-mixing soil improvement increases horizontal stiffness resulting in a stiffer response of superstructure and reduction of pile stress during earthquakes. The influence of SPSI on superstructure and comparisons between simulation cases are then discussed. However, this study does not consider consolidation and the contraction properties have been simplified.
\end{abstract}

\section{Keywords: 3D FEM/ABAQUS/ Seismic/ Soil-pile-structure interaction}

\section{INTRODUCTION}

Nowadays, the number of high-rise buildings in Thailand is increasing dramatically, especially in Bangkok, the capital of Thailand. Most of the design methods in Thailand are based on the assumption that the foundations of the building are assumed to be rigid or fixed. This kind of simplification can reduce the complication of the problem and also reduce the time required to analyze the problem, thus this simplification can help engineers to work easier and also save the cost for designing the building. However, this simplification is excluding soil-structure interaction and the flexibility of soil and foundation will be ignored.

Many design codes suggest neglecting the soilstructure interaction. Neglecting SSI is usually considered beneficial because the soil-structure interaction can increase the damping of the structural system. In addition, a lot of previous research found that SSI is reasonably neglected for low-rise structures and structures supported with very stiff soil. However, SSI will have a significant influence on a structure that is supported with soft soil, especially for high-rise buildings [1-4].

Even though the Bangkok area is located in a low seismic hazard zone, most of the soil profiles at a shallow depth are soft soils that are potentially influenced by far distance earthquakes. Since SSI has a high influence on the upper structure subjected to seismic load, post-seismic records in the past such as 1985 Mexico City, 1994 Northridge, and 1995 Kobe earthquakes provided adequate reasons to prove that the SSI effects should be investigated $[5,6]$.

Cement mixing is one of the cost-effective soil improvement techniques that can improve the strength and stiffness of the weak soil area [7]. The improved area of the surrounding soil can potentially reduce the negative effect of SSI by increasing the horizontal stiffness. Moreover, additional numerical analyses to validate this approach are needed.

In the past, most of the numerical research about SSI was simplified to be linear elastic in order to reduce the complication of the problem. As computer hardware improved a lot over the past few years, FEM software also improved and allow computers to analyze non-linear problems with great efficiency. Even though some of the previous research implements a non-linear soil model with non-linear Winkler spring models to the SSI problem, the effect of SSI is still not clearly understand. Winkler spring model is the spring model based on the Winkler spring theory which uses beam elements to model the pile and uses the spring element to model the soil along the embedded pile surface. This model will consider only the load and displacement of the soil 
and springs are independent of each other which excludes shear coupling between the springs.

In this study, a powerful engineering numerical simulation program based on the finite element method, ABAQUS, is adopted to simulate the 3D SSI behavior of pile foundations subjected to seismic load with the continuum SSI model. This continuum model will include normal pressure, shear drag, and gap/slap mechanism between soil and pile which provides reliable responses when compared to other approaches [8]. The response of the structure is then observed.

\section{RESEARCH SIGNIFICANCE}

This study aims to investigate the effects of SoilStructure Interaction on a medium high-rise building and compare the effects of strengthening for lateral resistance of the pile foundations in soft soil with the cement-mixing method, as less time consuming and less expensive method. When increasing the lateral resistance, it is expected that the dynamic response of the building can be stiffer at ground level and diminish the beneficial effects of the SSI on the superstructure as well as create a different stress state in the existing pile foundations. The SSI problem is analyzed considering the gap-slap effect which occurs between the foundations and the soft soil.

\section{APPROACH FOR SOIL-STRUCTURE INTERACTION IN NUMERICAL ANALYSIS}

\subsection{Soil-Structure Interaction Interface Properties}

According to previous research, the most suitable interface properties for SSI are the combination of normal behavior (Pressure-Over closure) and Tangential behavior [8,9]. In the past, most SSI model was based on the Winkler spring theory, but recently many researchers developed the SSI model to be compatible with continuum model such as gap element. The behavior of SSI was modeled as surface contact behavior between subsoil and pile. The master surface and slave surface are assigned to pile and soil respectively.

\subsubsection{Normal Behavior (Pressure-Over Closure)}

Normal behavior is defined as Pressure-Over closure that is transmitted between soil and pile while both surfaces are in contact with each other. The most appropriate type of normal behavior is "hard contact". Hard contact means that there is a zero-penetration condition between each surface. In addition, if surfaces are in contact, any contact pressure can be transmitted between them. The surfaces separate if the contact pressure reduces to zero. Separated surfaces come into contact when the clearance between them reduces to zero. in other words, this behavior will allow the gap/slap mechanism to occur. 3.1.2. Tangential Behavior

The most suitable tangential behavior for SSI is penalty friction. Unlike the spring model, this type of friction can provide drag force to the system. This friction model is based on Coulomb friction. As the basic theory of the Coulomb friction model, two surfaces that contacting to each other can carry shear drag stress up to a certain point across their interface before they start sliding relative to one another. The Coulomb friction model defines this critical shear stress, $\tau$, at which sliding of the surfaces starts as a fraction of the contact pressure, $\mathrm{p}$.

$$
\tau_{c r i t}=\mu p
$$

Where $\mu$ is known as the coefficient of friction. The coefficient of friction, $\mu$, is equal to $\tan (\delta)$ where $\delta$ is the interface frictional angle of the soils [10]. The interface frictional angle $(\delta)$ was estimated using the equation as shown in Eq. (2) [11].

$$
\delta=\tan ^{-1}\left[\sin \phi^{\prime} \cos \phi /\left(1+\sin ^{2} \phi\right)\right]
$$

\subsection{Simulation of Shaking Table}

To demonstrate the soil-structure interaction behavior such as gap/slap mechanism, the numerical analysis approaches are calibrated by simulating the physical model shaking table test. A flexible wall container on a shaking table is proven to be accurate and provides the best response spectra when compared to other types of shaking table containers. Thus, a single pile model with a flexible wall container shaking table test was adopted as a reference case [12]. The single pile model with superstructure is the best model to observe soil-pilestructure interaction behavior. The single pile model with head masses of 25, 100, and $160 \mathrm{lbs}$. The piles were subjected to Loma Prieta earthquake motion with a maximum horizontal acceleration of $0.16 \mathrm{~g}$. The numerical model assembly of the shaking table is shown in Fig. 1.

The boundary conditions in the numerical model are the same as a flexible wall barrel container. At the bottom of each confining ring and rubber membrane, the displacements are restrained in the vertical direction and will allow to move freely in the horizontal direction. The combination of confining ring and rubber membrane confined the soils and help the soil maintain its geometry. The soil model is displacement restrained with roller support in the vertical direction at the bottom of the model.

The result from the simulation shows a good correlation with the observed from the experiment as shown in Fig.2. Most of the soil-structure interaction 
effects can be observed such as Gap/slap mechanism and the influence of the kinematic forces from the soil to the pile, and the influence from the inertial forces from the super-structure.

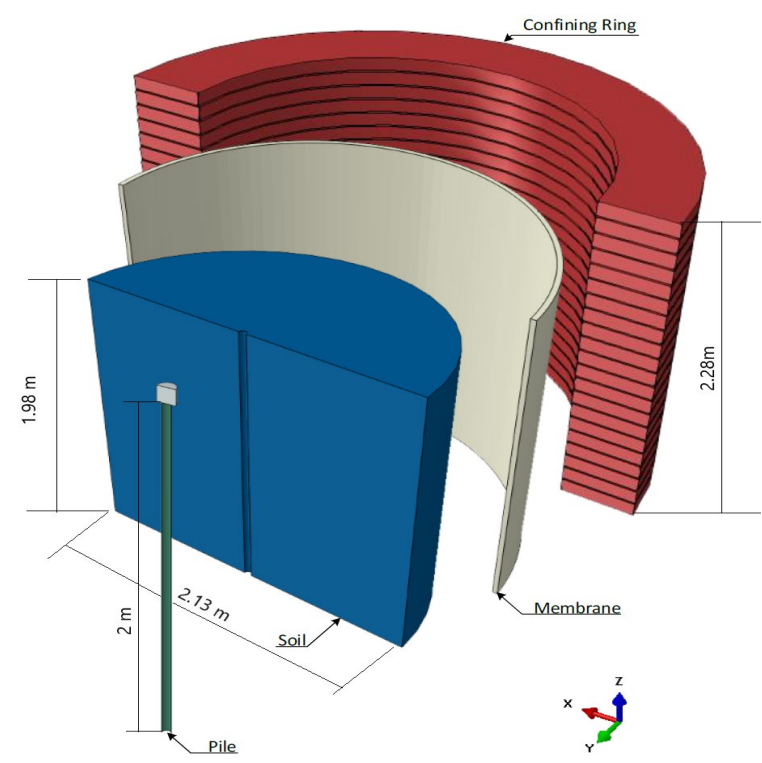

Fig.1 Numerical model assembly of shaking table.

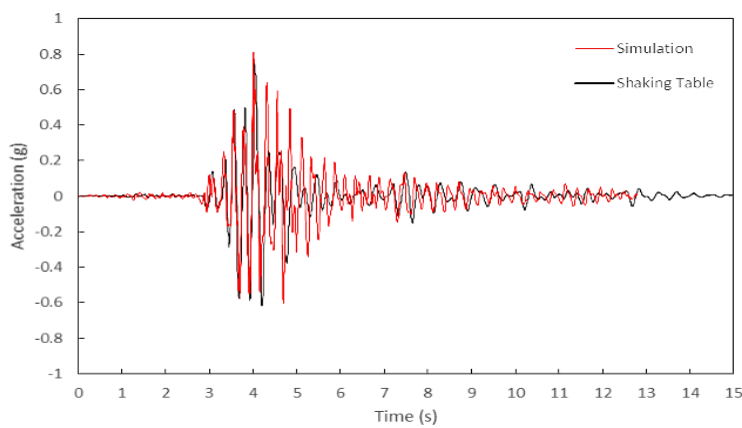

Fig. 2 Acceleration time history at the pile head with 160 lbs. mass.

Figure 3 shows the gap/slap mechanism which causes free vibration and reduction of pile stiffness. Even though some results have a small deviation, it can be confirmed that physical shaking table test with flexible wall barrel container can be successfully simulated by using 3-D FEM program, ABAQUS.

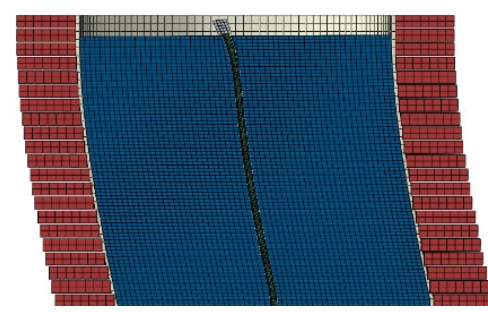

(a)

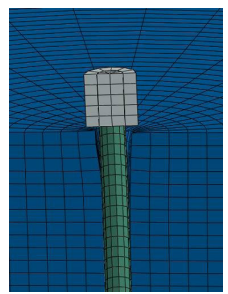

(b)
Fig.3 Gap deformation (a) during earthquake motion (b) permanent deformation.

\section{ANALYSIS OF SOIL-PILE-STRUCTURE INTERACTION}

The modeling technique used the contact properties from the calibration model to simulate the effect of SSI on the Pile-foundation system and superstructure. This model includes a pile foundation system and an 18-floor building with natural periods of 1.79 and $1.44 \mathrm{~s}$ in $\mathrm{x}$ and $\mathrm{y}$ direction, respectively. The superstructure in this study is simplified from an existing 18-floor building, for the purpose to achieve symmetry in both axes. The earthquake motion is applied to both directions of the building. Floor to floor height of the superstructure was $3 \mathrm{~m}$., with 1.5 $\mathrm{m}$. clearance between the first floor and the ground level. The superstructure composes of columns, beams, slabs, elevator shafts, and footings. The columns have two different sizes of a cross-section which are $0.4 \times 0.8 \mathrm{~m}$. and $0.4 \times 0.15 \mathrm{~m}$. The slab thickness is $0.25 \mathrm{~m}$. The beam cross-section including the slab thickness is $0.5 \times 0.25 \mathrm{~m}$. Figure 4 shows the foundation system of the superstructure consists of several types of pile and piled-raft footings, with a pile length of $40 \mathrm{~m}$., and a pile cap thickness of $1.7 \mathrm{~m}$.

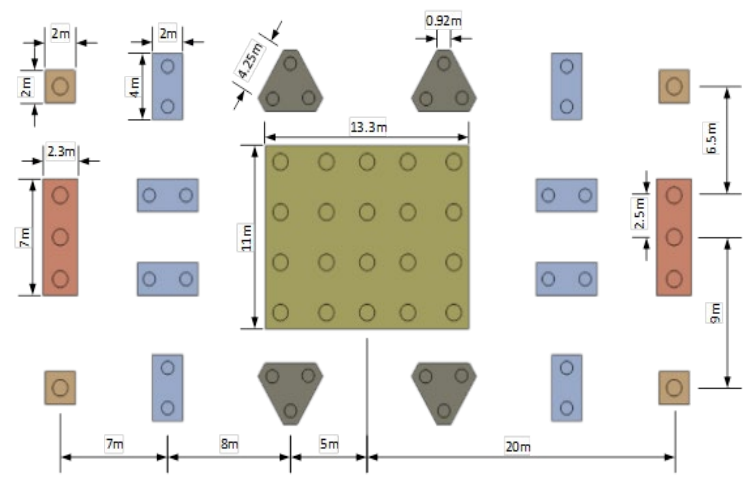

Fig.4 Foundation system layout of the superstructure.

The soil layer boundaries in this study are $235 \mathrm{~m}$ deep and $100 \mathrm{~m}$ in diameter. The superstructure has 18 stories with a combined height of $55.5 \mathrm{~m}$. The building has a width of $18.8 \mathrm{~m}$. and a length of $40.4 \mathrm{~m}$. as shown in Fig. 5. The boundary conditions in this part are similar to the previous one. The soil parameters in this study are adopted from previous researches $[13,14]$. The material properties and soil parameters are shown in Table 1.

Figure 6 shows three cases that consider in this study which are (1) structure only; (2) structure with soil layers; and (3) structure with cement-mixing improved soil

The third case attempts to increase the horizontal stiffness of the foundation system of the superstructure by using a soil cement mixing method $[15,16]$. The interaction was applied to all contact surfaces including the contact surface between cement mixing soil and existing soil. 
Table 1 Material properties and soil parameter (Likitlersuangetal et al., 2013; Arai and Yamazaki, 2002)[13,14]

\begin{tabular}{|c|c|c|c|c|c|c|c|c|}
\hline Material & $\begin{array}{l}\text { Depth } \\
\text { (m) }\end{array}$ & Model & $\begin{array}{c}\gamma \\
\left(\mathrm{kN} / \mathrm{m}^{3}\right)\end{array}$ & $\begin{array}{c}\mathrm{Su} \\
(\mathrm{kPa})\end{array}$ & $\begin{array}{l}\text { Friction } \\
\text { Angle }(\phi)\end{array}$ & $\begin{array}{l}\mathrm{Eu}, \mathrm{E} \\
(\mathrm{mPa})\end{array}$ & $\mathrm{v}$ & $\begin{array}{l}\text { Rayleigh } \\
\text { damping }\end{array}$ \\
\hline \multicolumn{9}{|l|}{ Soil } \\
\hline Soft Clay1 & $0-7.5$ & MCM & 16.5 & 20 & - & 10 & 0.5 & $5 \%$ \\
\hline Soft Clay2 & $7.5-12$ & MCM & 16.5 & 39 & - & 20.5 & 0.5 & $5 \%$ \\
\hline Medium Clay & $12-14$ & MCM & 17.5 & 55 & - & 27.5 & 0.5 & $5 \%$ \\
\hline Stiff Clay1 & $14-20$ & MCM & 19.5 & 80 & - & 40 & 0.5 & $5 \%$ \\
\hline Sand & $20-21.5$ & MCM & 19 & - & 27 & 53 & 0.5 & $5 \%$ \\
\hline Stiff Clay2 & $21.5-26$ & MCM & 20 & 120 & - & 72 & 0.5 & $5 \%$ \\
\hline Hard Clay1 & $26-60$ & MCM & 20 & 240 & - & 240 & 0.5 & $5 \%$ \\
\hline Hard Clay2 & $60-235$ & MCM & 20 & 400 & - & 1350 & 0.5 & $5 \%$ \\
\hline $\begin{array}{l}\text { Cement } \\
\text { mixing }\end{array}$ & - & $\mathrm{MCM}$ & 16 & 300 & - & 221.9 & 0.5 & $5 \%$ \\
\hline Concrete & & LEM & 23 & & & 35000 & 0.2 & $5 \%$ \\
\hline Confining Ring & & Rigid & 0 & - & - & - & - & - \\
\hline Membrane & & LEM & 0 & - & - & Vary* & - & - \\
\hline
\end{tabular}

* Elastic modulus of the Membrane depends on the soil layer

** MCM = Mohr-Coulomb Model

** LEM = Linear Elastic Model

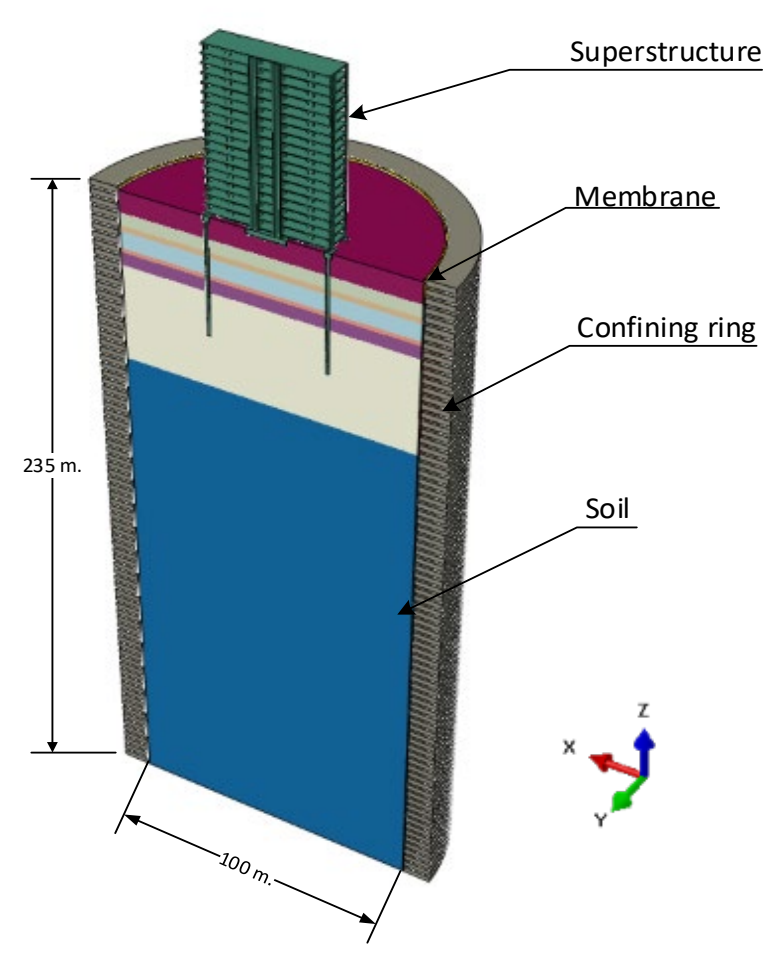

Fig.5 Assembly of SPSI model with a high-rise building.

The model was subjected to the Loma Prieta earthquake as shown in Fig.7. The earthquake time history is applied at bottom of the model in Case 2 and Case 3 while the acceleration time history obtained from the free-field analysis is applied to the bottom boundary of Case 1 . The earthquake wave was propagating from the bottom to the soil surface.
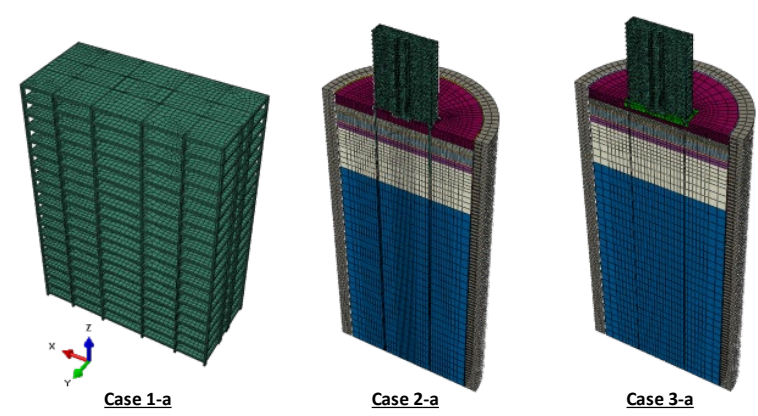

Fig.6 Assembled 3-D model and mesh of analysis case 1-3.

As the wave travels through different soil layers, the wave was modified by transfer functions as shown in free-field motion analysis. Thus, the wave propagation in this model was more realistic than the model that applied the earthquake motion at the side boundary of the model. After the model was subjected to earthquake time history, permanent gap formations are clearly observed on most of the footing and piles.

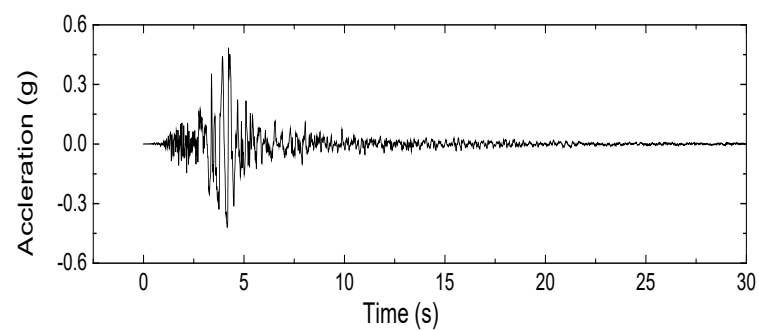

Fig.7 Acceleration time history of Loma Prieta Earthquake, Gilroy Array, 1989. 


\section{RESULTS}

The acceleration time history and spectral acceleration of both cases are shown in Fig. 8 and Fig. 9. In the case2-a, superstructure vibrates in modes 1 through 4. Due to SPSI, the frequency of vibration for case 2 was lower than the case 1 . In case 2 , where SPSI is included in the analysis, the vibration frequency of the superstructure was shifted from $0.57 \mathrm{~Hz}$ to $0.5 \mathrm{~Hz}$ for mode 1 and $0.69 \mathrm{~Hz}$ to $0.53 \mathrm{~Hz}$ for mode 2. Figure 9 shows a comparison of acceleration time history between case 1 and case 2 . The soilstructure-interaction provides additional damping and flexibility to the superstructure, thus the amplitude of acceleration was lower and the period increased [1]. The SSI also reduced the relative displacement of the superstructure. The gap/slap mechanism can be observed in Fig.10. Once the gap is forming the unconfined area of the piles and footings increases, which leads to an increase in the natural period of the superstructure.

The acceleration time history and spectral acceleration for cases 2 and 3 are shown in Fig. 11 and Fig. 12. The vibration characteristic between case 2 and case 3 is almost similar, however, ground improvement by using cement-mixing can increase the stiffness of the weak soil layer which results in a stiffer response from the superstructure.

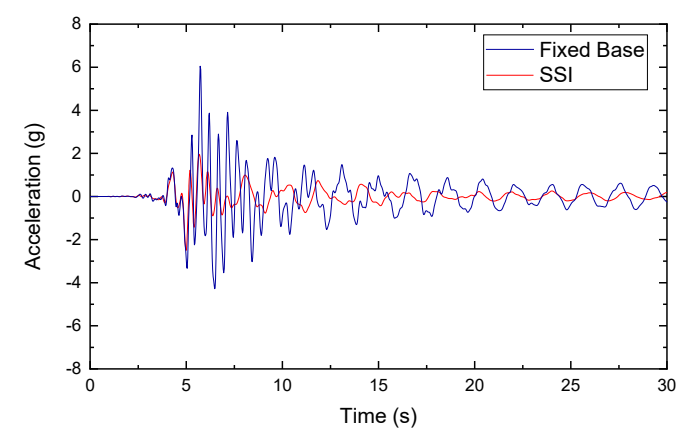

Fig. 8 Comparison of acceleration time history between case $1-a$ (Fixed Base) and case 2 -a(SSI) at the top of the superstructure.

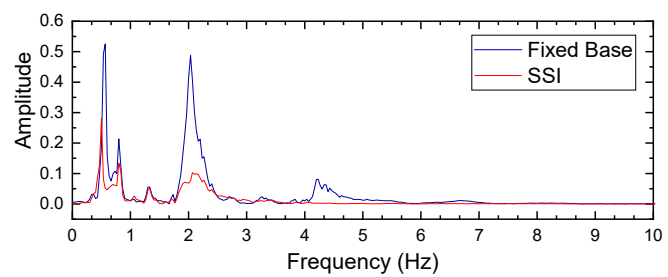

Fig.9 Comparison of spectral acceleration between case $1-\mathrm{a}$ (Fixed Base) and case 2-a(SSI) at the top of the superstructure.

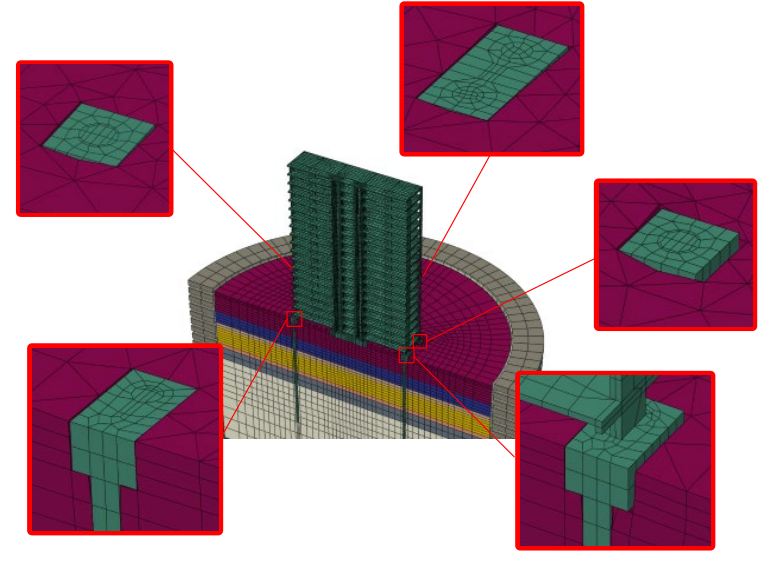

Fig.10 Permanent gap around footings in case 2-a.

Since there is a very high number of piles in this study, some of the piles were selected from each type of footings to show the change of vertical stresses during the earthquake. The vibration of the superstructure generates a significant amount of bending moment on the piles. The stresses in each pile are shown in Fig.13 and Fig.14. The cementmixing soil improvement increases the horizontal stiffness of the soil which resulted in better axial stress distribution among the piles. When the gap is formed, the unconfined area increasing and the influence from the moment from the superstructure to the pile also increases.

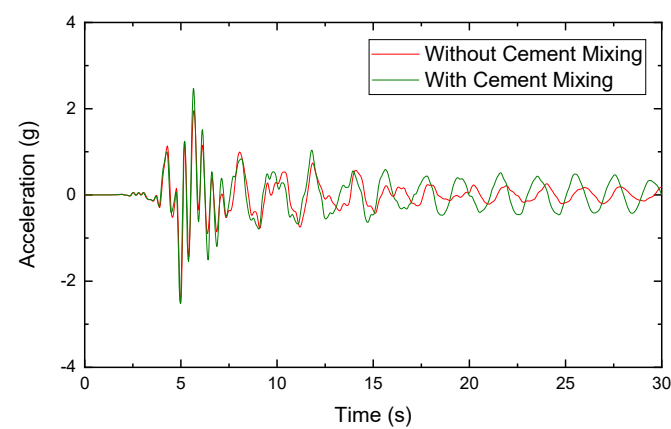

Fig.11 Comparison of acceleration time history between case 2-a and case 3-a at the top of the superstructure.

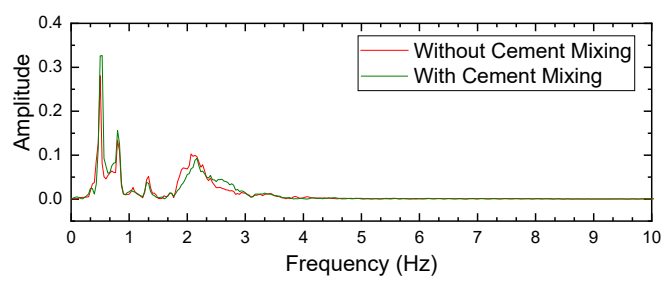

Fig. 12 Comparison of spectral acceleration between case 2-a and case 3-a at the top of the superstructure. 


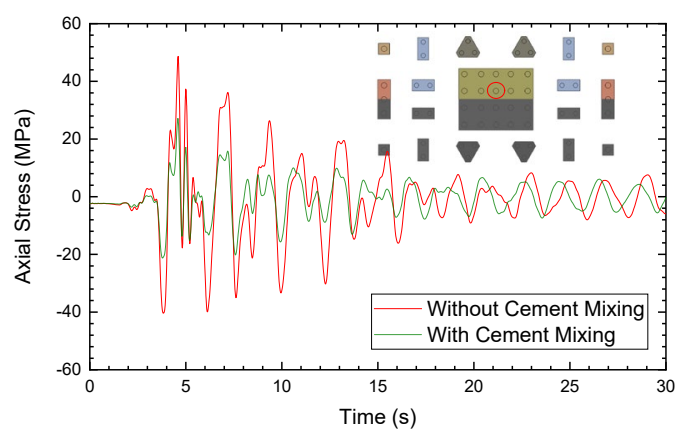

Fig. 13 Comparison of the axial stresses between case 2-a and case 3-a for the pile in the middle of pile raft.

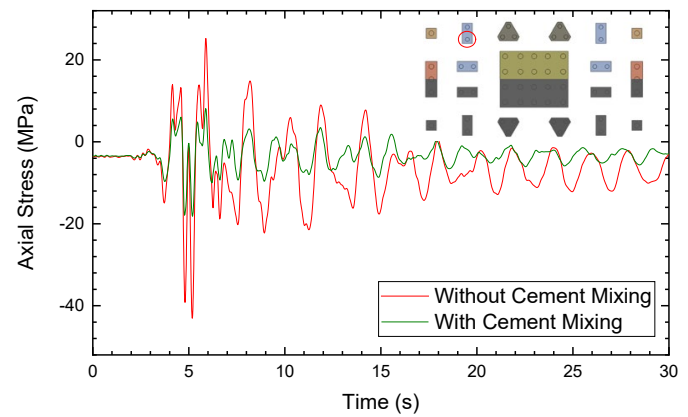

Fig. 14 Comparison of the axial stresses between case 2-a and case 3-a for the pile of 2-pile footing.

As the cement-mixing increases the strength and stiffness of the surrounding soil, the gap deformation is reduced. Although most of the stress in the piles decreased due to the cement-mixing soil improvement, the efficiency of cement-mixing also depends on the non-improved soil. The elastic modulus and cohesion between improved area and non-improved soil are significantly different, thus the gap can be observed between the contract surfaces as shown in Fig. 15.

The comparison of bending moment between the case with and without ground improvement are shown in Fig. 16. The overall bending moment of the case with ground improvement is slightly higher due to the stiffer response of the superstructure.

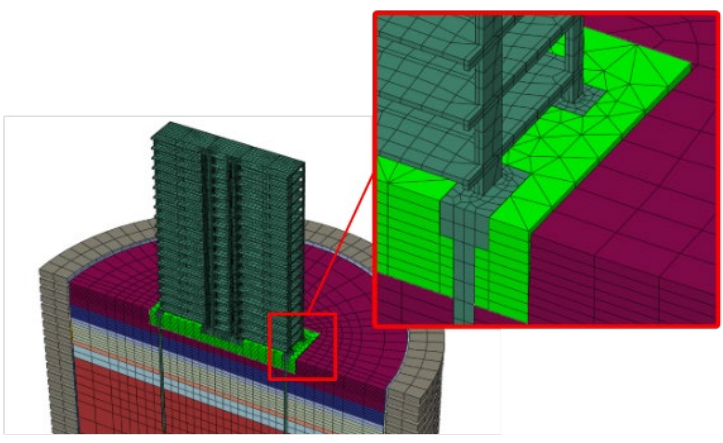

Fig.15 Permanent gap between cement-mixing and environmental soil in case 3 -a.

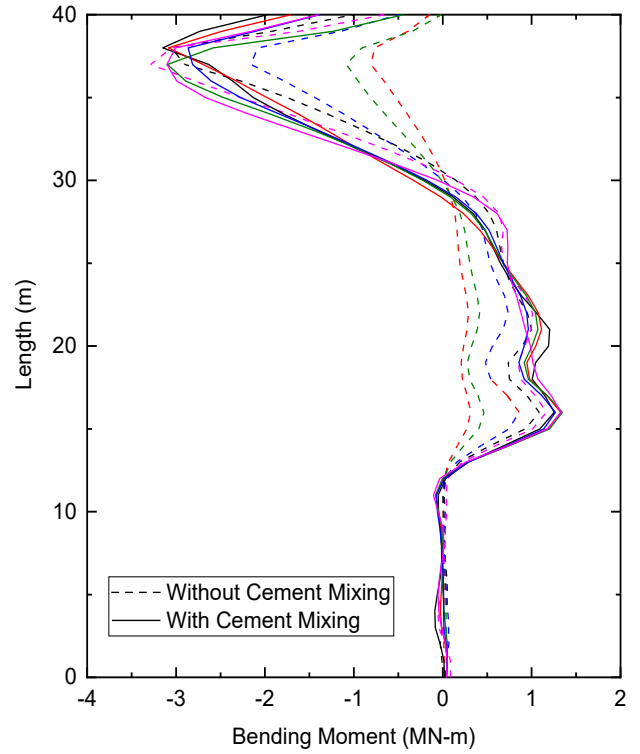

Fig.16 Comparison of overall pile bending moment between case 2 -a and case $3-\mathrm{a}$ at maximum relative displacement.

However, ground improvement provides better bending moment distribution and lowers the bending moment concentration on one individual pile as shown in Fig. 17a. The bending moment is distributed uniformly among the piles in the improved area which will increase the bending moment in some of the piles that have lower bending moment as shown in Fig. 17b.

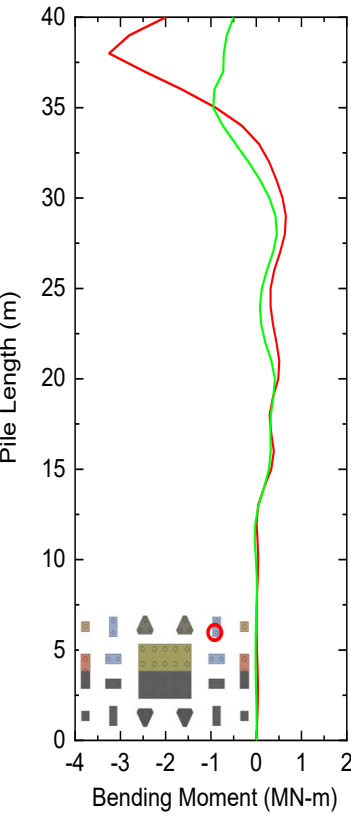

(a)

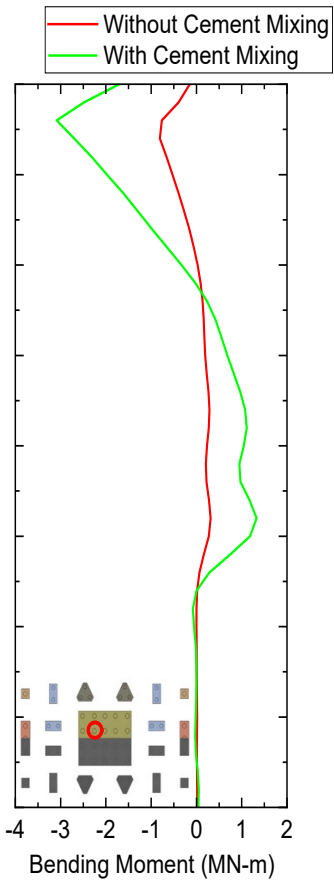

(b)
Fig. 17 Comparison of pile bending moment between case 2 -a and case 3 -a 


\section{CONCLUSION}

Soil-pile-structure interaction behavior can be successfully simulated by using 3-D finite element software "ABAQUS". The gap/slap mechanism was clearly observed. Soil-pile-structure interaction provides damping and flexibility to the superstructure. The natural period of the superstructure was increased. The acceleration and displacement of the superstructure were significantly decreased. Cementmixing soil improvement increases the horizontal stiffness of the foundation system which results in better stress and uniform bending moment distribution among the piles which significantly reduces the bending moment concentration in individual piles, and the gap position was changed from the contract surfaces between soil and piles to contact surfaces between non-improved soil and cement-mixing soil.

\section{ACKNOWLEDGMENT}

The authors would like to express their gratitude for financial support from King Mongkut's University of Technology Thonburi (KMUTT) through The Petchra Pra Jom Klao Ph.D. scholarship under contract Grant No. 2/2559.

\section{REFERENCES}

[1] Guin J. and Banerjee P. K., Coupled soil-pilestructure interaction analysis under seismic excitation, Journal of Structural Engineering, Vol. 124, No. 4, 1998, pp. 434-444.

[2] Mylonakis G. and Gazetas G., Seismic soil structure interaction: Beneficial or Detrimental, Journal of Earthquake Engineering, Vol. 4 No.3 2000, pp. 277-301.

[3] Han Y., Seismic response of tall building considering soil-pile-structure interaction, Earthquake Engineering and Engineering Vibration, Vol. 1, 2002, pp. 57-64.

[4] Saha R., Dutta S. C. and Haldar S., Seismic response of soil-pile raft-structure system, Journal of Civil Engineering and Management, Vol 21, No.2, 2015, pp. 144-164.

[5] Mizuno H., Iiba M. and Hirade T., Pile damage during the 1995 Hyogoken-Nanbu earthquake in Japan, 11th World Conf. on Earthquake Engineering, Association for Earthquake Engineering (IAEE), Tokyo, No. 977, 1995, pp. 1129-1130.

[6] Phanikanth V., Choudhury D. and Reddy G., Behavior of Single Pile in Liquefied Deposits during Earthquakes, International Journal of Geomechanics, 2013, pp. 454-462.
[7] Rollins K. and Brown D., Design Guidelines for Increasing the Lateral Resistance of HighwayBridge Pile Foundations by Improving Weak Soils, National Cooperative Highway Research Program Report, Washington, D.C., 2011, pp. 697

[8] Andreotti G, Calvi GM., Design of laterally loaded pile-columns considering SSI effects: Strengths and weaknesses of 3D, 2D, and 1D nonlinear analysis, Earthquake Engng Struct Dyn., 2021, Vol 50, pp. 863-888.

[9] Lv Y., Liu H., Charles W.W. Ng, Ding X. and Gunawan A., Three-dimensional numerical analysis of the stress transfer mechanism of XCC piled raft foundation, Computers and Geotechnics, Vol. 55, 2014, pp. 365-377.

[10]Lee C. J., Bolton M. D. and Al-Tabbaa A., Numerical modeling of group effects on the distribution of dragloads in pile foundations, Geotechnique, Vol. 52, No. 5, 2002, pp. 325-335.

[11]Randolph M.F. and Wroth C.P., Application of the failure state in undrained simple shear to the shaft capacity of driven piles, Geotechnique, Vol. 31, 1980, pp. 143-57.

[12]Meymand P.J., Shaking Table Scale Model Tests of Nonlinear Soil-Pile-Superstructure Interaction In Soft Clay, Doctor of Philosophy Dissertation, University of California, Berkeley, 1998.

[13]Likitlersuang S., Surarak C., Wanatowski D., Oh E. and Balasubramaniam A., Finite element analysis of a deep excavation: A case study from the Bangkok MRT, Soils and Foundations, Vol. 53, No.5, 2013, pp. 756-773.

[14]Arai H. and Yamazaki F., Exploration of S-Wave Velocity Structure Using Microtremor Arrays in the Greater Bangkok, Thailand, EDM Technical Report No.15, Earthquake Disaster Mitigation Research Center (EDM), 2002.

[15]Rollins K. and Brown D., Design Guidelines for Increasing the Lateral Resistance of HighwayBridge Pile Foundations by Improving Weak Soils, National Cooperative Highway Research Program Report, Washington, D.C., 2011, pp. 697.

[16] Muraleetharan K.K., Ravichandran N. and Norton S.L., Fully Coupled Dynamic SoilStructure Interaction Analysis of Pile Foundation in Weak Soil, 4th International Conference on Earthquake Geotechnical Engineering, No. 1177, 2007.

Copyright (C) Int. J. of GEOMATE All rights reserved, including making copies unless permission is obtained from the copyright proprietors. 